\title{
Integrating renewable energy sources by electric vehicle fleets under uncertainty
}

\author{
Katrin Seddig*, Patrick Jochem, Wolf Fichtner \\ Karlsruhe Institute of Technology (KIT), Institute for Industrial Production (IIP), Chair of Energy Economics, Hertzstr. 16, D-76187, Karlsruhe, Germany
}

Keywords:

Electric vehicle fleets

Renewable energy sources

Uncertainty

Load management

Stochastic optimization

\begin{abstract}
A B S T R A C T
Electric vehicles are one of the concepts towards green and sustainable transportation systems. However, several uncertainties with respect to electricity demand and availability of electric vehicles as well as electricity supply by renewable energy sources influence an optimal scheduling through smart charging strategies. This paper investigates the possibilities to integrate additionally loads of uncertain renewable energy sources by smart charging strategies of three different electric vehicle fleets namely, com mercial customers, commuters, and opportunity parkers. Therefore, data from an empiric field test with a public charging infrastructure in a parking garage with a photovoltaic system is taken. Various stra tegies are analyzed, considering the changing individual electricity demand, restrictions and parking times of electric vehicle fleets by combining a Monte Carlo simulation approach with different meth odologies like a heuristic algorithm, an optimization model and stochastic programming. The numerical results indicate that the domestic photovoltaic generation of the car park can be fully used by the electric vehicle fleets for charging and the utilization of photovoltaic can be doubled when comparing uncon trolled and optimized charging strategies. The commuter fleet has the highest $\mathrm{CO}_{2}$ emission reduction potential of all three electric vehicle fleets. Moreover, load management decreases costs, even when uncertainties are considered.
\end{abstract}

\section{Introduction}

Overall, there is a decreasing trend of $\mathrm{CO}_{2}$ emissions in the Eu ropean Union (EU). However, the transport sector is the only one which has not lowered its $\mathrm{CO}_{2}$ emissions since 1990 [1]. Hence, alternative vehicles technologies can play an important role in reducing these and other local emissions. Especially a transition to electric vehicles (EV) can support this objective. This would also result in a diminishing oil dependency.

Apart from that, an increasing share of electricity generation from renewable energy sources (RES) has a positive impact on the overall reduction of EU's $\mathrm{CO}_{2}$ emissions. In Germany, the ongoing energy transition leads already to a significant shift from electricity generation by fossil fuels to RES. However, the power generation by RES comes along with an undesired fluctuation of the supply side. In this context charging strategies from EV - i.e. flexible loads could support a smooth integration of RES and stabilization of the grid - especially due to their long idle times [2].

\footnotetext{
* Corresponding author.

E-mail address: katrin.seddig@kit.edu (K. Seddig).
}

This aspect on integrating RES through EV exists already in the literature. There are many approaches to increase the share of RES through scheduled EV charging e. g. Tabatabaee et al. (2017) [3] elaborates the combination of RES and EV in the context of the local distribution system or Sehar et al. (2017) [4], apply demand management for an integration of photovoltaic (PV) in the charging process of EVs and therefore, reducing peak demand in the envi ronment of a retail building. The main driver for most research in this field is that EVs can provide a double dividend: the flexibility of electricity demand is increased and the environmental impact of EV is decreased when charging them with RES generated power. Thereby the cost awareness could be analyzed from different per spectives such as car users (e.g. to reduce costs), electricity pro viders (e.g. to increase profit) or grid operators (e.g. reduce generation costs). The minimization of charging costs is the focus of this paper, additionally to the RES integration and the corre sponding $\mathrm{CO}_{2}$ reduction potential.

The analysis of this paper is based on data from an empiric field test with a public charging infrastructure in a parking garage with a PV system [5] and analyzes various strategies with and without the stochastic components of RES provision. The individual changing 
electricity demand, restrictions and parking times of EV fleets are considered by combining a Monte Carlo simulation (MCS) approach with different methodologies like a heuristic algorithm, a mixed integer linear program (MILP) and a stochastic MILP (SMILP) which consists of a two stage stochastic optimization model with sample average approximation method. The resulting different costs for each approach are compared to each other.

The objective of this paper is to maximize the utilization of PV generation through smart charging strategies of EV fleets in a parking garage at minimal charging costs. Additionally, un certainties in PV generation, charging behavior characteristics (time and amount) of different EV fleets are considered in the modeling.

The remainder of this paper is organized as follows: Section 2 'Related work' gives a literature overview, section 3 'Data and research design' presents the structure of the use case as well as the sources and the uncertainties from the data used. In section 4 'Methods' the applied three main approaches and their algo rithms are introduced. In section 5 the results are reported and discussed as well as some policy implications are given. Section 6 draws conclusions, shows limitations, summarizes the paper and gives an outlook for potential future research.

\section{Related work}

The reduction of charging costs can be one of the main drivers for EV owners to schedule their chargings. Only a few contributions in the research field are found, which address stochastic pro gramming. Li et al. (2012) account for the stochastic variables but they reproduce the stochastic terms within scenarios [6]. In Soares et al. (2017) stochastic programming is used to evaluate electricity pricing schemes for EVs. Their study indicates that with an adequate demand response scheme the profitability of a business model based on energy aggregation can be improved [7].

When it comes to different methodological approaches used in the EV charging context, the review paper of Rahman et al. (2016) gives a broad insight of existing optimization models [8]. Several papers compare different charging strategies, including heuristics vs. smart charging strategies with respect to self consumption of electricity from own PV systems, e.g. Refs. [9], [10]. Not only opti mized scheduling strategies are applied, but also different algo rithm can be used to determine optimized schedules, e. g. Ref. [11]. In Jochem et al. (2015b) a MILP approach is compared to a two stage greedy algorithm in the setting of the combination of EVs and micro combined heat and power units. The MILP solution might be more accurate, however, the benefit of the algorithmic approach is that the computational time is reduced [12].

Utilization of RES through smart charging of EVs is another common topic. For instance, Gottwalt et al. (2013) show that EV charging load can be shifted towards RES generated electricity. They use a MILP with full information and as a result, they could show that they can double the share of RES through an optimized charging schedule [13]. Especially the literature on solar energy is much more diverse than wind as the local generation and afterward directly usage through EVs provides interesting methods [14]. Agent based modeling is also a widely used approach for modeling e. g. the load curves of EV and showing the interaction on a national energy system. For instance, Novosel et al. (2015) apply MATSim to identify the impact of EVs and the intermittent RES penetration on Croatia's energy system [15].

However, adding the interplay of the stochastic characteristics of EVs and RES generation, this should be considered carefully as there is still little research in this area. Uncertainties for the RES are covered by using different stochastic approaches like Markov chains [16] or time series modelling [17] to have a forecast for the electricity generation by PV. In Tushar et al. (2014) additionally to the PV prediction for the next $24 \mathrm{~h}$ with Markov Chains, the EVs arrival time is modeled as a Poisson Process. Their model is applied in a microgrid including home appliances with the goal to minimize the needed imported electricity from the microgrid. Saber and Venayagamoorthy (2012) had a closer look into resource sched uling of EVs and RES under uncertainty in a smart grid. In their paper, they use a Particle Swarm Optimization to minimize emis sions and costs and for the uncertainties, scenarios are considered [18].

Honarmand et al. (2014) propose already a method for inte grating EVs into a smart grid with RES in a context of a parking lot [19] and additionally taking the battery condition into consider ation [20]. They have a closer look on reserve and energy sched uling using a MILP to minimize the operating costs. They do not consider the probabilistic nature of EVs with respect to arrival and departure time [19]. In Figueiredo et al. (2017) the charging process of EVs through solar energy in a car park is examined by applying a Genetic Algorithm Optimization to test different business models [21]. The methodology of game theory is also represented in the context of an EV parking lot with respect to maximizing the profit of a car park operator by Ref. [22]. Through managing the charging and discharging process of plug in hybrid EVs accordingly the highest profits for the utility owners can be achieved. Braam et al. (2016) apply a MILP to evaluate the load shift potential for EVs for a parking garage. They account for several restrictions of this envi ronment and use PV generated power for charging, however, their system only includes $13 \mathrm{EVs}$. They do not take into consideration any uncertainties involved (neither RES generation nor EV driving profiles [23]). Furthermore, other research had been done in the context of charging of EVs in parking garages with the interaction of RES, however, they consider one homogenous type of EV fleet only [24] or no uncertainties [25].

This paper extends the existing literature by considering the charging behavior of the EV according to its field of application: commercial customers, commuters, and opportunity parkers. These three different EV fleets are characterized by different driving and charging profiles using at the same time a common public charging infrastructure. Therein empirical data is used. The approach of this paper is to identify the corresponding load shift potentials of these different fleets in the context of maximizing own consumption of electricity from PV under uncertain envi ronmental parameters using stochastic programming and addi tionally minimize the charging costs.

\section{Data and research design}

This section presents the use case set up with the three EV fleets and PV generation in the parking garage (section 3.1) and the data including their underlying uncertainties (section 3.2).

\subsection{Use case}

The use case of this paper is a mid size car garage for about 650 cars located in central Stuttgart, Germany. The generic set up of the use case can be seen in Fig. 1.

The first considered fleet category is the commercial fleet, which consists of a carpool of different commercial EVs, i.e. a company fleet. Thereby, only day trips are considered for business concern. Typically, the cars are available for charging overnight.

The second fleet is operated by commuters, i.e. usually long term customers living or working nearby. This includes people who drive regularly, mainly on weekdays, from home to work and back with their private car. Looking at their driving profiles, they usually depart (arrive) between 6 and 9 a.m. and arrive (depart) 


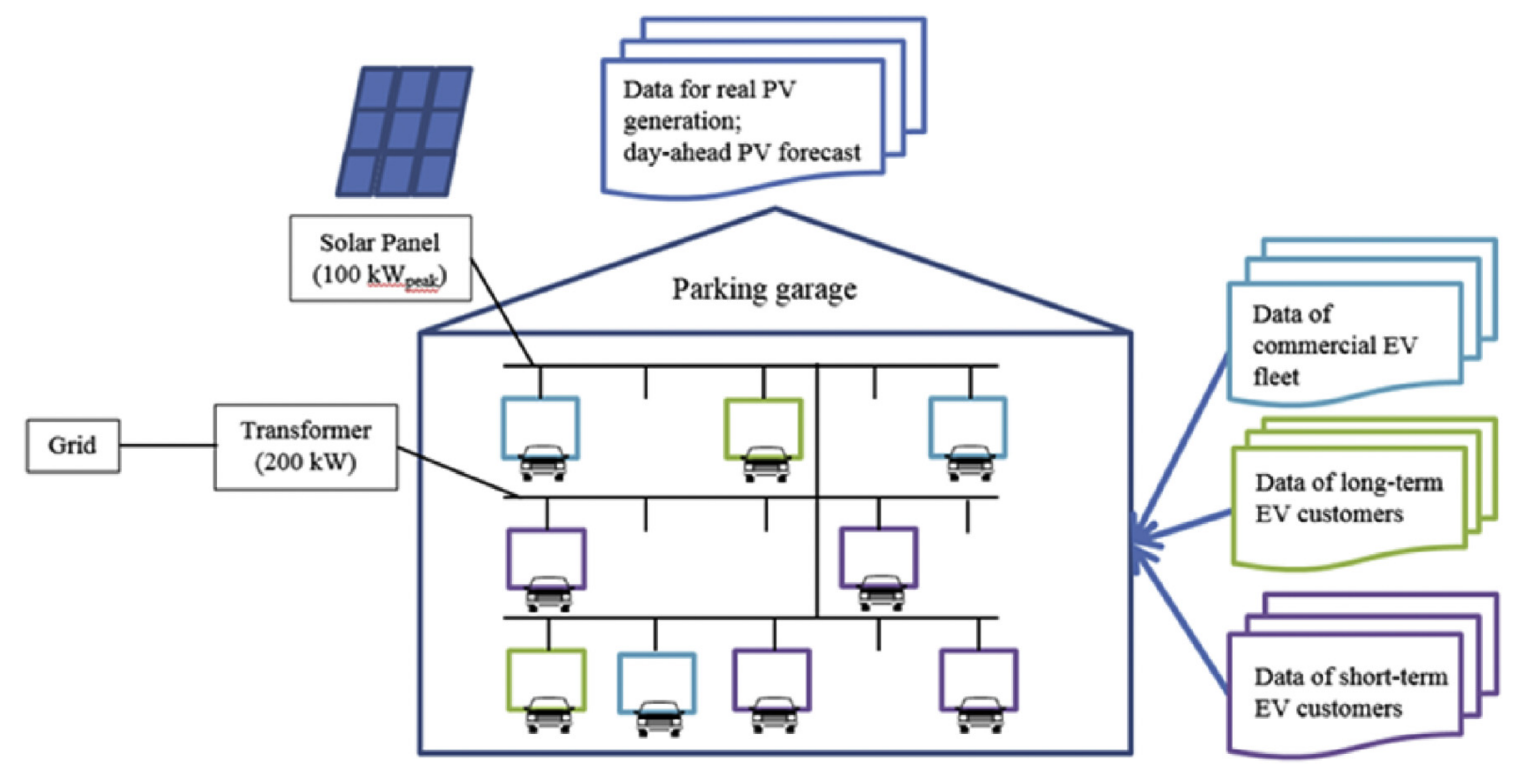

Fig. 1. Model of the parking garage use case.

around 6 p.m. at weekdays. Therefore, commuters have two different time slots for charging the EV. The first one is at home, looking at around $14 \mathrm{~h}$ of parking time during the night. The second possibility for charging is during work time having round about $8 \mathrm{~h}$ for charging during daytime. In this paper, the focus is on the second group of commuters, which park during the day in a parking garage and do not consider the other sub group.

Thirdly, the other fleet of private cars which is looked at is referred to as short term or opportunity customers. In this context, their characteristics are that they drive shorter distance and usually park at public or semi public places. This applies usually to leisure times and activities like shopping, cinema, sports, etc.

It is assumed that the charging infrastructure is shared between all the three types of EV fleets and every EV can charge at every charging point. More details regarding the data analysis can be found in Ref. [5].

\subsection{Data and uncertainties}

For this field test, comprehensive real data is available and used within the simulation model. The data consists of driving profiles from short term and long term customers of parking garage users in terms of arriving and departure time from a parking garage. This data is expanded and as a reference for the covered distances the German KiD data [28] was taken. This data is based on trips of combustion based engines vehicles. Hence, to adapt the data for an EV usage, an algorithm for decision support is used to select the trips which are possible to drive with an EV. The algorithm takes several assumed parameters for an EV into consideration e.g. bat tery capacity of $24 \mathrm{kWh}$ and average electricity consumption of $0.2 \mathrm{kWh} / \mathrm{km}$. This results in a maximum range of $120 \mathrm{~km}$ for the trips. The resulting driving patterns seem relative homogenous among the three EV fleets and most of the trips are shorter than $20 \mathrm{~km}$ [5]. The local charging power is set to a maximum of $11 \mathrm{~kW}$ and the batteries have a linear charging behavior.

For the PV, solar radiation data from the region Stuttgart for the

\footnotetext{
${ }^{1}$ As a reference EV the Nissan Leaf was chosen with a battery capacity of 24 kWh and an average electricity consumption of $20.39 \mathrm{kWh}$ per $100 \mathrm{~km}$ [33].
}

year 2013 is compiled. These data are used to generate synthetic driving profiles as well as feed in of RES with stochastically derived patterns.

To account for the uncertainties of the model the stochastic behavior of EV usage is described by a probability distribution of the different parameters. An EV driving pattern consists of three parameters, arrival time $\left(t_{a}\right)$, departure time $\left(t_{d}\right)$ and trip distance (r) taken from several data sources as mentioned above.

Based on these three parameters depending on the EV fleet a particular dataset is used to generate a probability density function (PDF). Kernel density estimation (KDE) is used to estimate in a non parametric way the PDF of the random variables. All PDFs of the three fleets are created with the same method. The distinguishing between the modelling of the three EV fleets is, that the short and long term customers have each a two dimensional KDE from the real time values of the car park concerning arrival time and parking duration. Additional they have a one dimensional KDE for the distances. The fleet customers have a three dimensional KDE for all three parameters $\left(t_{a}, t_{d}, r\right)$. The 90 queries of a day for each fleet are created by pulling out random triples (for the three parameters) of the generated PDFs. The number of queries ( 270 in total, 90 queries of each fleet) is a priori predetermined and the information is available before the 1000 simulations of each of the applied methodologies starts. The number of each EV fleet remains the same for each simulation run.

In general, the energy demand of each charging query $v$ about the energy needed for one trip is calculated by using the informa tion of the trip distance $r$ from each $\mathrm{EV} i$ in combination with the assumed electricity consumption $b$ of $0.2 \mathrm{kWh} / \mathrm{km}$, as specified in the following equation (1).

$v_{i} \quad r_{i} \cdot b \quad \forall \mathrm{i}$

It is assumed that the EVs have originally a battery state of charge (SOC) of $100 \%$ and then make one trip to the parking garage and afterward they will charge again until the SOC is full by $100 \%$ at the departure of the EV.

Uncertainties of electricity generation by PV rely mainly on clouds. Fig. 2 shows the intermittent character of the solar generated energy over the course of a day in the year 2013 for the Stuttgart region. There is an unpredictable nature of the PV 


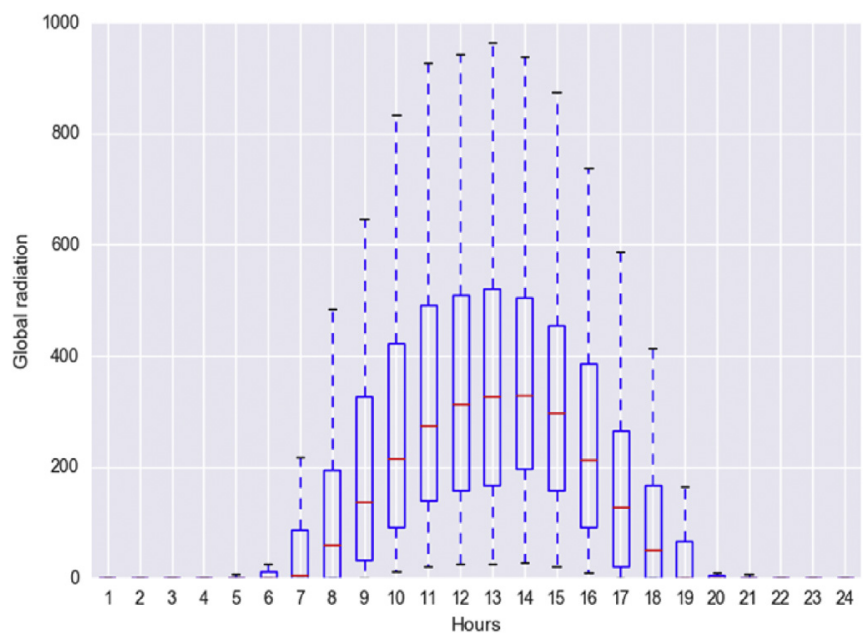

Fig. 2. Distribution of global radiation from the year 2013 over the length of a day for the Stuttgart region; Data source [34].

generation and the resulting energy output.

For the 1000 simulation runs every time one random day is taken out of the samples which are divided into summer (three months) and winter (three months) generated PV of the year 2013. In the following three different characteristics of PV generation will be used to represent the complexity of the integration of PV:

- Perfect Foresight: As a first strategy, (unrealistic) a priori known PV curves are used. The data source is taken from real observations for PV generation of one year from the Transnet $\mathrm{BW}$, which provides information for the region in the south of Germany [29].

- Day-Ahead Foresight: For the second strategy, again the data source from Transnet BW is used, however, they also provide data for prediction of the day ahead PV generation. Hence, the information of the expected day ahead PV generation in relation to the real observed PV generation of the same day is used.

- Historic Foresight: For the last strategy, empirical perturbed forecast curves reflecting the uncertainty are created. Therefore, data from over the last seven years of PV generation from the day ahead forecasts in comparison to the real observation are taken. Resulting from the time series data analysis are time dependent normal distribution which is applied as a noise to the expected day ahead forecast curves and create therewith the stochastic scenarios.

After identifying these three different characteristics of PV generation the utilization of the PV usage for charging the EVs can be analyzed in detail. Thereby, the application of different strategies including the various methodologies capture the uncertainties which are involved.

\section{Methods}

In this section, the focus is on the three main methodology approaches of the paper with a closer look on the applied algo rithms. Therein the content will include the developed heuristic, the simulation model, the optimization model without and with stochastic variables including the sample average approximation method.

\subsection{Simulation setup}

The parking garage and its rooftop have a potential for PV panels of about $100 \mathrm{~kW}_{\text {peak. }}$ A further assumption is that up to 90 cus tomers of each EV fleet exist and with charging queries of each fleet the parking garage utilization is modeled for every day. The model accounts for power limits within the vehicle itself ( $11 \mathrm{~kW})$, the charging infrastructure of each charging point $(11 \mathrm{~kW})$ and the grid connection $(200 \mathrm{~kW})$. Restrictions regarding the availability of charging stations are not considered. It is assumed that there exist as many charging points as EVs. However, there might arise a re striction due to the grid connection reflected through transformer limitations of the parking garage. Therefore, to consider the pos sibility of congestion of the parking garage, that no car is either able to enter or has no possibility for connecting to a charging point, an acceptance rate of the queries is introduced. The value is set by $95 \%$ of all the placed charging queries of the three EV fleets. Hence, not all charging queries will be accepted.

Furthermore, two power sources are considered with diverse supply costs. On the one hand, PV generated energy is valued with a price of zero as the marginal production costs of PV are zero. There is no feed in of the PV power to the grid. It is only used for self consumption to charge the EVs and it can be used instead of the electricity from the grid. This means the overall grid connection restriction of $200 \mathrm{~kW}$ remains all the time the same. On the other hand, the external needed electricity from the grid is weighted with prices from the whole sale electricity markets. They are taken from the year 2013 of the EEX spot intraday market, divided into summer and winter prices [26].

As described above, the three EV fleets are studied in a simu lation model to account for all the uncertain parameter involved. Several uncertainties of input variables are considered - departure and arrival time, the energy demand of each trip of each EV fleet and the EEX price which is linked to the electricity generation by PV (time and energy per day). Thereby, the potential of using own consumption from the PV system under cost minimization of the external needed charging power is identified. The implemented smart charging strategies consider different scenarios of an optimal integration of RES and hence achieve a high reduction of $\mathrm{CO}_{2}$ emissions. As a reference case, the average specific $\mathrm{CO}_{2}$ emissions of the German electricity grid of about 500 gr. $\mathrm{CO}_{2}$ per $\mathrm{kWh}$ is considered [27]. Therefore, during a sunny day, the specific $\mathrm{CO}_{2}$ emissions per $\mathrm{kWh}$ range between this extreme during the night and zero gram during noon (due to the PV system).

For evaluating the impact of RES eight different strategies are applied (see Table 1). This is due to the used methodologies including the different characteristics of PV as well as the deviation in summer and winter. Consistent with the existing approaches from the literature there are two main distinctions considered uncontrolled (i) as well as coordinated charging (ii - iv). The latter is divided in three different optimization models with respect to the PV inclusion through EV fleets and minimizing thereby the charging costs. This is used to optimally schedule the charging processes of the different EV fleets. As mentioned in section 3.2, it is distinguished between Perfect Foresight PV (ii), Day Ahead Fore sight PV (iii) and Historic Foresight PV (iv) generation. All the four strategies are evaluated for summer (a) and winter (b) season (i.e. different EEX prices and PV generation) leading to eight different results (i.e. costs for electricity demand from the grid).

For the charging coordination, all the information are available at the beginning of the simulation. To map the possibility of over night charging for the commercial fleet it is assumed that about half of the queries start the charging window from midnight to depar ture and the other half from arrival to midnight. This is since the simulation time horizon is $24 \mathrm{~h}$ and it should be possible to cover 
Table 1

Overview of the eight strategies within the used approaches.

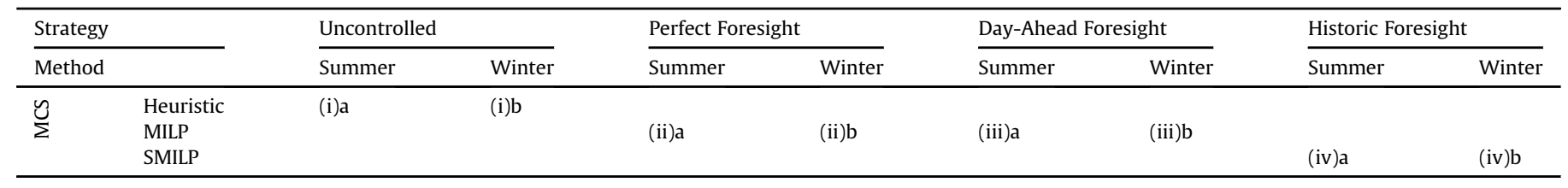

the low price times for charging for each fleet.

The optimization models consist of time slots of 15 min repre senting $24 \mathrm{~h}$ of one working day (representative data for analysis was Tuesday to Thursday), starting at 0:00 and finishing at 24:00. Hence, the model compromises 96 time slots. The simulation and optimization are focused on working days as two out of three of the considered EV fleets have mainly driving patterns during working days. The benchmark strategy (i) is the heuristic model of uncon trolled charging. The charging process starts as soon as the EV ar rives at the parking garage. Moreover, the charging power is constant over the charging process and considers the local as well as global wattage limitations. The overall costs are calculated by multiplication of the needed external charging power with the corresponding EEX prices during that time of day.

For all the models (heuristic and three optimization models) additionally, a MCS is applied to identify the impact of the variation of the three parameters $\left(t_{a}, t_{d}, r\right)$ involved due to the underlying PDFs. Therefore, 1000 runs of the MCS are done for each of the models. For every run of the MCS, there is a new set of queries (90 queries for each fleet) used for each of the three EV fleets as well as new daily PV generation to cope with the underlying PDFs of the regarding parameters. Moreover, the advantage of the MCS is that using the underlying PDFs of all the parameters a variety of different possible days are covered even though the simulation is only for $24 \mathrm{~h}$.

As mentioned above, the optimization models are combined with a simulation model to cover several days. Different EEX prices are respectively chosen for winter and summer days and one day is picked randomly out of about 90 possible summer days and the predicted PV forecast generation is chosen accordingly. This assumption is based on works of e. g. Ref. [30], where the authors found out that renewable energy generation has a linkage to the EEX price and is reflected in the curve shape of the EEX prices. For ensuring the comparability between the different models, initially an acceptance rate of the charging queries are set to $95 \%$ as a benchmark strategy. This is introduced as the possibility exists that not all EVs can be charged due to limitation of the global power or restrictions of the local power. If the queries of the three EV fleets are managed to be charged in the benchmark strategy (which is the heuristic model and no charging coordination takes place) they can also be charged in the optimization models. Hence, the same acceptance rate of queries has to be fulfilled by the optimization models.

\subsection{Optimization model}

The general objective function (2) minimizes the expenditures for electricity demand $x_{t}$ from the grid, evaluated with EEX prices $c_{t}$. This problem is formulated as a MILP.

$\min _{x} C \sum_{t}\left(c_{t} \cdot x_{t}\right)$

For strategy (ii) the optimal costs with a priori known PV gen eration can be determined. This is the benchmark case for the PV integration as there will only be one optimization. This result of the optimization is the global optimum as perfect information is assumed. Table 2 provides an overview of the model parameters.

For a comprehensive comparison of the different strategies (ii) (iv) a 2nd optimization step objective (3) is introduced. This ac counts for the deviation from day ahead forecasted and realized PV generation.

$$
\min _{x} C \sum_{t}\left(a \cdot c_{t} \cdot\left|\begin{array}{ll}
x_{t}^{\text {real }} & x_{t}
\end{array}\right|\right)
$$

The 1st stage objective remains the same corresponding to the objective function (2). Costs for the planned external needed charging power are calculated based on the day ahead forecasted $\mathrm{PV}$. In a second step as the day with its PV generation is realized the 2nd optimization step objective kicks in. The already made decision regarding the purchase of electricity is taken as input in compari son to the real needed external electricity. Thereby, deviation in which additional external charging power is needed is evaluated with penalty costs. The deviation penalty $a$ is a factor which is assumed to be two and is multiplied with the corresponding EEX prices. This deviation calculation is based on the assumption that it will be more expensive to buy the remaining external electricity intraday than day ahead. The summation of both objectives leads to the final costs for the strategy (iii).

The optimization programs (ii - iv) are subject to the following constraints:

$\sum_{\mathrm{t}} \frac{1}{4} \cdot \mathrm{p}_{\mathrm{i}, \mathrm{t}} \quad \mathrm{d}_{\mathrm{i}} \quad \forall \mathrm{i}$

$\mathrm{d}_{\mathrm{i}} \quad \mathrm{q}_{\mathrm{i}} \cdot \mathrm{v}_{\mathrm{i}} \quad \forall \mathrm{i}$

$\mathrm{p}_{\mathrm{i}, \mathrm{t}} \geq 0 \quad \forall \mathrm{i}, \mathrm{t}$

$\sum_{\mathrm{i}} \mathrm{p}_{\mathrm{i}, \mathrm{t}} \leq \mathrm{GW} \quad \forall \mathrm{t}$

Table 2

Definitions of variables, parameters and indices.

\begin{tabular}{lll}
\hline $\begin{array}{l}\text { Variables, Parameter, } \\
\text { Indices }\end{array}$ & Description & Unit \\
\hline $\mathrm{c}$ & Intraday EEX-Price & $\mathrm{ct} / \mathrm{kWh}$ \\
$\mathrm{x}$ & External charging power & $\mathrm{kW}$ \\
$\mathrm{q}$ & Binary if query is served & Dimensionless \\
$\mathrm{d}$ & Demand & $\mathrm{kWh}$ \\
$\mathrm{p}$ & Charging power & $\mathrm{kW}$ \\
$\mathrm{v}$ & Query demand & $\mathrm{kWh}$ \\
$\mathrm{a}$ & Deviation penalty & Dimensionless \\
$\mathrm{PV}$ & PV power & $\mathrm{kW}$ \\
$\mathrm{GW}$ & Global Wattage of transformer of & $\mathrm{kW}$ \\
$\mathrm{LW}$ & parking garage & \\
$\mathrm{t}$ & Local Wattage of charging points as $\mathrm{w}$ & $\mathrm{kW}$ \\
$\mathrm{i}$ & Index for time steps & Dimensionless \\
\hline
\end{tabular}


$\mathrm{p}_{\mathrm{i}, \mathrm{t}} \leq \mathrm{LW} \quad \forall \mathrm{i}, \mathrm{t}$

$\mathrm{x}_{\mathrm{t}} \geq 0 \quad \forall \mathrm{t}$

$x_{t} \geq \sum_{i} p_{i, t} \quad P V_{t} \quad \forall \mathrm{t}$

Constraint (4) ensures that the sum of all the charging's (re flected by the charging power $p_{i, t}$ ) equals the demand $d_{i}$ of all the accepted queries (introduced through the binary variable $q_{i}$ and the corresponding query demand $v_{i}$ ), which is described by constraint (5). Charging power $p_{i, t}$ of each EV $i$ is a limit at all times $t$ to the local wattage $L W$ (constraint (8)) and in the model set by $11 \mathrm{~kW}$. Further constraints are that the charging power $p_{i, t}$ as well as external needed charging power $x_{t}$ is positive (constraints (6) and (9), respectively). The charging power $p_{i, t}$ of each vehicle $i$ is limited at all times $t$ through the global wattage $G W$ of the transformer from the parking garage which is enforced via constraint (7). This leads to an upper limit in the summation of all parallel executed charging processes. The external needed charging power $x_{t}$ is introduced by constraint (10) and results from the difference be tween the overall charging demand and the PV power output $P V_{t}$.

\subsection{Two stage stochastic optimization with sample average approximation method}

Adding now uncertainties to the MILP can lead to different ap proaches to solving the stochastic problem. It is assumed that there are two stages, first the purchase of electricity day ahead and second after the realization of the intraday. Therefore, the approach of the two stage stochastic optimization is used and includes the sample average approximation method [31].

The objective of strategy (iv) is to minimize the cost of the 1st stage decision plus the expected cost of the 2nd stage decision, which can be formalized as follows:

$\min _{x} \sum_{t}\left(\left(c_{t} \cdot x_{t}\right)+E_{\omega} Q(x, \omega)\right)$

The latter expression is the recourse term. This is the expecta tion $E$ of the 2 nd stage objective function $Q$. Therein, the recourse costs of the stochastic variable for the PV generation are minimized. There is a recourse decision variable for the missing external needed charging amount $x$. The expectation function of the ex pected cost can be approximated by the sample average

$q_{N}(x) \quad \frac{1}{N} \sum_{j}^{N} Q\left(x, \omega^{j}\right)$

with scenarios $\omega^{\mathrm{j}}, \mathrm{j} \quad 1, \ldots, \mathrm{N}$ with uniform probability $\mathrm{p}_{\mathrm{j}} \quad 1 / \mathrm{N}$ assumed [32].

Herein the scenarios are generated using the time dependent normal distributed perturbed forecast curves. Thereby, the Latin hypercube sampling technique is utilized for the generation of the scenarios and it is applied for variance reduction. This leads to the following expression:

$\min _{x} \sum_{t}\left(c_{t} \cdot x_{t}\right)+\frac{1}{N} \sum_{j}^{N} Q\left(x, \omega^{j}\right)$

This formulation is a SMILP. In this use case, 200 scenarios for the recourse term are applied. The stochastic variable of the PV generation is only present in the objective function (11). Hence, the existing constraints remain the same but the values of the variables are now depending on the scenarios and the SMILP follows the constraints (4)-(10)

Similar to strategy (iii) the overall costs are calculated in applying the objective (2) to account for the deviation of the real ization of the day and add this cost to the calculated ones with stochastic programming.

\section{Results and discussion}

The model is applied to evaluate direct load control to increase the integration of RES and additionally minimize the charging costs for the remaining needed charging energy under uncertainty.

\subsection{Load characteristics}

Fig. 3 shows the load curves of the three EV fleets which include all accepted charging queries of all the three EV fleets. The line of the curves shows the medians of the 1000 simulation runs of the strategy (i)a and the shaded surface are the areas of the $25 \%$ and $75 \%$ quantiles and this represents the variation of each parameter due to the underlying PDFs. The uncoordinated charging case re flects the different driving patterns of the EV fleets and the un derlying assumptions of the models. As soon as the EVs are connected and there is enough energy available, they start charging. Commuters (blue area) arrive in the morning hours and have their charging peak at that time. Short term customers (green area) use a parking garage more often during afternoon hours which is reflected by higher charging demand during that time of the day. With the underlying assumption of the model that some of the commercial fleet customers start charging at midnight and some of them after the end of their trip, two peaks arise during the day.

In Fig. 4 the different load curves for the strategy (iii)a are dis played. Similar as in the graph before the line of the curves show the medians of the 1000 MCS runs of the optimization model and the shaded surface are the areas of the $25 \%$ and $75 \%$ quantiles. In comparison to uncoordinated charging load shifting takes places with respect to PV utilization and taking advantage of lower elec tricity prices. All the three EV fleets show the flexibility to shift their load profile. The commercial fleet customers (pink area) are able to charge overnight, where electricity prices are low. Not surprisingly due to the long idle time of long term customers (blue area) can this fleet be shifted towards the generated PV power during the day. Hence, the long term customers are the fleet which takes the highest share of PV for charging. This is represented by the highest

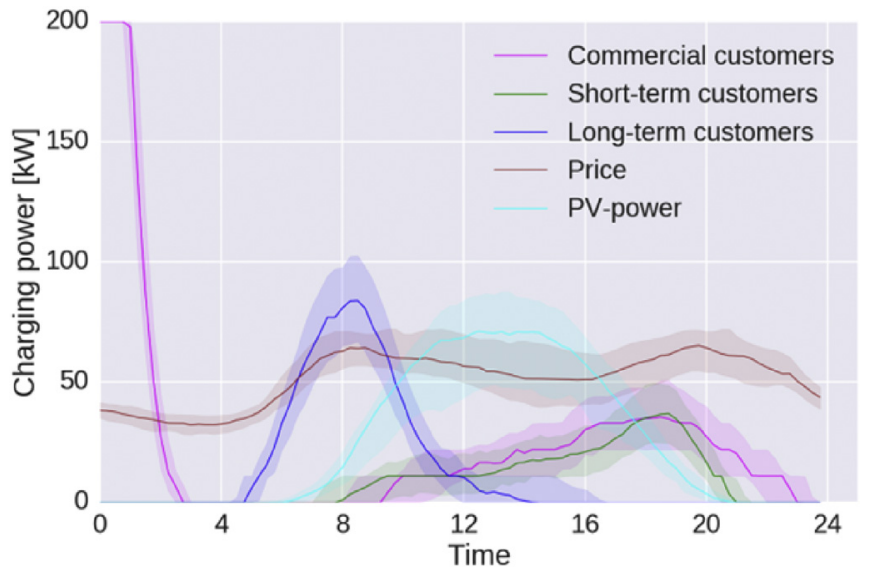

Fig. 3. Load distribution for uncontrolled charging, heuristic (with median curve; $25 \%$ \& $75 \%$ quantile shaded areas). 


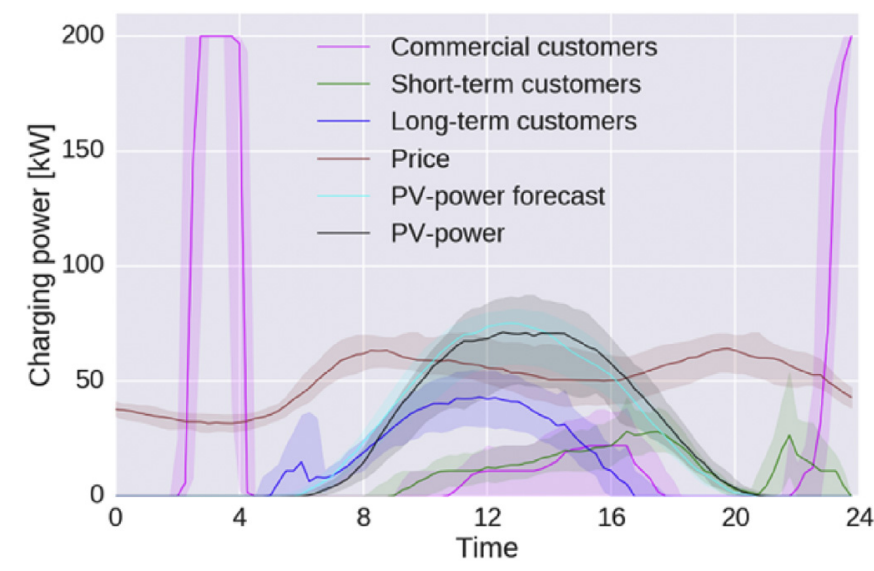

Fig. 4. Charging load distribution of the three EV fleets after optimization with respect to PV integration and charging cost minimization (with median curve; $25 \%$ \& $75 \%$ quantile shaded areas).

load curve and the biggest share of the area underneath the load curve of the long term customers during hours of PV generation. The peak from the morning hours of charging is shifted towards the noon hours. PV power forecast follows close the patterns of the real PV output. Other papers show similar results for the comparison of uncontrolled and controlled charging for one EV fleet [27].

\subsection{Evaluation of the strategies}

In Fig. 5 the distribution of the costs of all eight strategies can be seen. For comparison, the highest costs which arise naturally in the uncontrolled charging strategy are set in comparison to the three PV integration strategies (ii - iv). As expected, the lowest of all the compared strategy costs are the one of the a priori known PV. For the strategies (iii), (iv) additional costs due to the derivation from the real PV output arises. Strategy (iv) could achieve a slight cost advantage in comparison to strategy (iii). Hence, the usage of sto chastic information gives an improvement of the cost results. In general, due to the underlying uncertainties of several parameters there exists a wide spread of at least $10 \%$ for the costs in the summer months. The range is smaller in the winter months as the PV effect is reduced. Comparing left and right panel, it is intuitive that winter costs are higher than summer costs. During the winter months, there is less PV available and consequently, more external power is needed to be purchased. The generated PV energy and the PV utilization of the eight strategies are shown in Fig. 6. During winter months PV can be fully utilized in every strategy and in the summer months the optimized strategies (ii - iv) can use in average about double of the PV generated energy in comparison to uncontrolled charging. For the increase of own consumption of electricity generated by PV, the optimization strategies (ii - iv) differ in average by about $10 \%$ in the summer months.

For the calculation of the $\mathrm{CO}_{2}$ emission reduction potential the German average $\mathrm{CO}_{2}$ emission factor for the energy mix of about 500 gr. $\mathrm{CO}_{2}$ per $\mathrm{kWh}$ is used. This results in average in a $\mathrm{CO}_{2}$ emission reduction potential on a sunny day in the uncontrolled strategy about $125 \mathrm{~kg} \mathrm{CO}_{2}$ in comparison of about $240 \mathrm{~kg} \mathrm{CO}_{2}$ for the perfect foresight strategy. Moreover, according to Fig. 4 the long term customer EV fleet has the highest PV usage potential for charging.

\subsection{Implication for research and policy}

This analysis shows, how important fleets of EVs can be with respect to $\mathrm{PV}$ integration and hence, $\mathrm{CO}_{2}$ reduction potential. Moreover, the interaction of uncertainties in driving patterns, un certainty in electricity generation by RES and different forecasting methodologies are analyzed and the results show that every EV fleet can utilize PV generated power for charging and that they all have load shifting potential.

For policy makers, it might be interesting to see the load shifting potential from each fleet of EVs at common used public charging infrastructures. Hence, fleet specific incentives can be developed to charge at special times for a best possible way of locally integrating RES. The results imply that it is possible, that different fleets of EV can share a charging and parking infrastructure, which leads to a

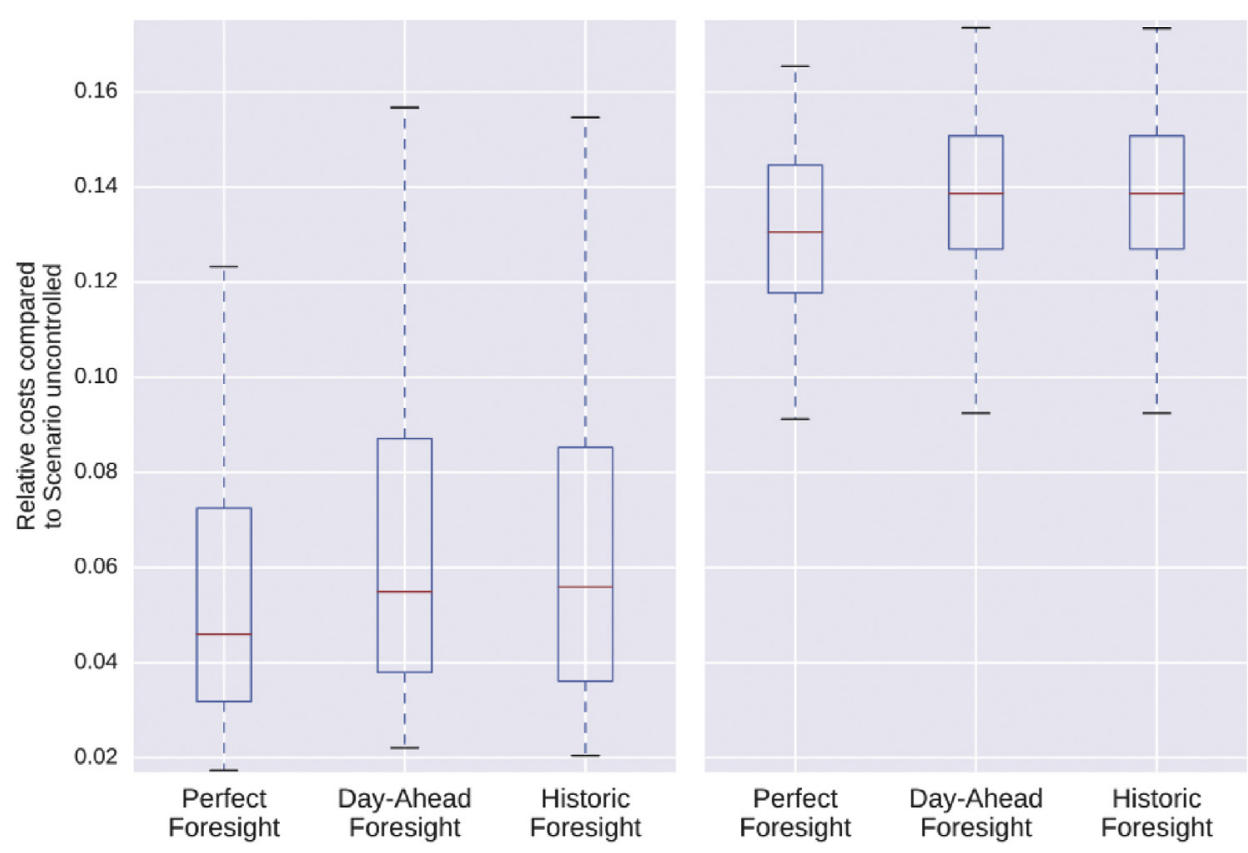

Fig. 5. Comparison of the costs of the eight strategies (summer (left) vs winter (right)). 

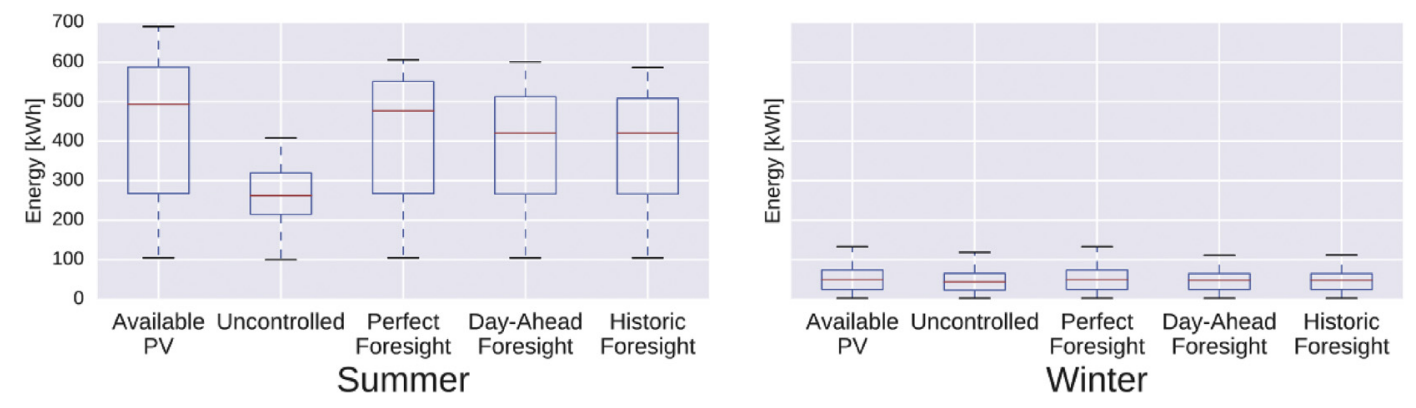

Fig. 6. Comparison of the PV utilization of the eight strategies.

reduced demand in charging infrastructure. Moreover, expensive grid expansions can be reduced. However, for an empirical appli cation of the developed approach different price concepts need to be introduced and evaluated.

\section{Conclusion and outlook}

The increasing share of EVs and electricity generated by RES increases the uncertainty of loads in the distribution grid. This issue is tackled by this paper and compares different developed models which compromise various methodologies from simulation, opti mization and stochastic programming in order to maximize the share of electricity from RES through charging three different EV fleets in a parking garage. This paper addresses the possibility of the load shifting potential from three different EV fleets and their contribution to a reduction in oil usage in the transport sector and $\mathrm{CO}_{2}$ emissions in the energy sector by supporting the integration of RES.

Results imply that stochastic programming with perturbed forecast curves of PV can achieve cost reductions in comparison to day ahead forecasted PV. All three EV fleets use PV power for charging - even under uncertainty of the generation by RES. The utilization of RES can be nearly doubled when comparing uncon trolled to optimized charging strategies. Due to PV generation winter costs are higher than summer costs. Long term customers (commuters) have the highest $\mathrm{CO}_{2}$ emission reduction potentials of all three EV fleets which is consistent with the fact that this fleet has the greatest potential for load shifting towards PV generated power. During the day, they can offset generated PV energy. Overall the three EV fleets could reduce the $\mathrm{CO}_{2}$ emissions on an average summer day by $240 \mathrm{~kg} \mathrm{CO}$ if the German average $\mathrm{CO}_{2}$ emission factor for the energy mix is applied. EV fleets can be used for load management and with the shown quantification of the load flexi bility and the cost savings this could lead to welfare enhancements.

A limitation of the model can be seen in constant battery charging, not every EV would charge necessarily, as most likely every trip is possible as they all have a high SOC and maybe it questionable that they charge $100 \%$. Moreover, the set of combi nation of EV fleets at the parking garage can be different elsewhere. This would lead to different results in terms of the PV utilization. Depending on the chosen size of the EV fleets there might not be enough EVs to fully use the electricity from the PV unit. An improvement of scenario generation for uncertainties can be un dertaken if there is more PV data available.

Additionally, an enhancement of the model could be the inte gration of a battery storage system which could be a new option for energy services connected to grid balancing.

Another use case could be wind integration through EV fleets as it appears that these three EV fleets provide also during nights considerable load shift potential. Hence, during the nights it is possible to fill valleys from low demand. The base load would be stabilized. Moreover, developing incentives to charge at special times for integrating local RES should be of special interest. Further user incentives and cost calculation could be applied. For instance, focusing on the cost minimization from the perspective of the parking garage operator might be promising.

\section{References}

[1] Eurostat. Smarter, greener, more inclusive? Indicators to support the Europe 2020 strategy. 2015.

[2] Ehsani M, Falahi M, Lotfifard S. Vehicle to grid services: potential and applications. Energies 2012;5:4076 90. https://doi.org/10.3390/en5104076.

[3] Tabatabaee S, Mortazavi SS, Niknam T. Stochastic scheduling of local distribution systems considering high penetration of plug-in electric vehicles and renewable energy sources. Energy 2017;121:480 90. https://doi.org/10.1016/ j.energy.2016.12.115.

[4] Sehar F, Pipattanasomporn M, Rahman S. Demand management to mitigate impacts of plug-in electric vehicle fast charge in buildings with renewables. Energy 2017;120:642 51. https://doi.org/10.1016/j.energy.2016.11.118.

[5] Seddig K, Jochem P, Fichtner W. Fleets of electric vehicles as adjustable loads facilitating the integration of electricity generation by renewable energy sources. In: Proc. 37th IAEE int. Conf. New York: Proceedings of the 37th IAEE International Conference; 2014. p. 1 16. p.

[6] Li Y, Kaewpuang R, Wang P, Niyato D, Han Z. An energy efficient solution: integrating Plug-In Hybrid Electric Vehicle in smart grid with renewable energy. In: 2012 IEEE conf comput commun work; 2012. p. 73 8. https:// doi.org/10.1109/INFCOMW.2012.6193522.

[7] Soares J, Ghazvini MAF, Borges N, Vale Z. Dynamic electricity pricing for electric vehicles using stochastic programming. Energy 2017:122:111 27. https://doi.org/10.1016/j.energy.2016.12.108.

[8] Rahman I, Vasant PM, Singh BSM, Abdullah-Al-Wadud M, Adnan N. Review of recent trends in optimization techniques for plug-in hybrid, and electric vehicle charging infrastructures. Renew Sustain Energy Rev 2016;58: 1039 47. https://doi.org/10.1016/j.rser.2015.12.353.

[9] Schuller A, Flath CM, Gottwalt S. Quantifying load flexibility of electric vehicles for renewable energy integration. Appl Energy 2015;151:335 44. https:// doi.org/10.1016/j.apenergy.2015.04.004.

[10] van der Kam M, van Sark W. Smart charging of electric vehicles with photovoltaic power and vehicle-to-grid technology in a microgrid; a case study. Appl Energy 2015;152:20 30. https://doi.org/10.1016/ j.apenergy.2015.04.092.

[11] Rahbari O, Vafaeipour M, Omar N, Rosen MA, Hegazy O, Timmermans J-M et al. An optimal versatile control approach for plug-in electric vehicles to integrate renewable energy sources and smart grids. Energy 2017. https:// doi.org/10.1016/j.energy.2017.06.007.

[12] Jochem P, Schonfelder M, Fichtner W. An efficient two-stage algorithm for decentralized scheduling of micro-CHP units. Eur J Oper Res 2015;245: 862 74. https://doi.org/10.1016/j.ejor.2015.04.016.

[13] Gottwalt S, Schuller A, Flath C, Schmeck H, Weinhardt C. Assessing load flexibility in smart grids: electric vehicles for renewable energy integration. In: 2013 IEEE power energy soc gen meet; 2013. p. 1 5. https://doi.org/ 10.1109/PESMG.2013.6672854.

[14] Richardson DB. Electric vehicles and the electric grid: a review of modeling approaches, Impacts, and renewable energy integration. Renew Sustain Energy Rev 2013;19:247 54. https://doi.org/10.1016/j.rser.2012.11.042.

[15] Novosel T, Perkovi L, Ban M, Keko H, Puk T, Kraja G. Agent based modelling and energy planning e Utilization of MATSim for transport energy demand modelling. Energy 2015;92:466 75. https://doi.org/10.1016/ j.energy.2015.05.091.

[16] Tushar KHM, Assi C, Member S, Maier M. Smart microgrids: optimal joint scheduling for electric vehicles and home appliances. IEEE Trans Smart Grid 2014;5:239 50.

[17] Pedro HTC, Coimbra CFM. Assessment of forecasting techniques for solar 
power production with no exogenous inputs. Sol Energy 2012;86:2017 28 . https://doi.org/10.1016/j.solener.2012.04.004.

[18] Saber AY, Venayagamoorthy GK. Resource scheduling under uncertainty in a smart grid with renewables and plug-in vehicles. IEEE Syst J 2012;6:103 9 . https://doi.org/10.1109/JSYST.2011.2163012.

[19] Honarmand M, Zakariazadeh A, Jadid S. Integrated scheduling of renewable generation and electric vehicles parking lot in a smart microgrid. Energy Convers Manag 2014;86:745 55. https://doi.org/10.1016/ j.enconman.2014.06.044.

[20] Honarmand M, Zakariazadeh A, Jadid S. Optimal scheduling of electric vehicles in an intelligent parking lot considering vehicle-to-grid concept and battery condition. Energy 2014;65:572 9. https://doi.org/10.1016/ j.energy.2013.11.045

[21] Figueiredo R, Nunes P, Brito MC. The feasibility of solar parking lots for electric vehicles. Energy 2017;140:1182 97. https://doi.org/10.1016/ j.energy.2017.09.024.

[22] Aghajani S, Kalantar M. A cooperative game theoretic analysis of electric vehicles parking lot in smart grid. Energy 2017;137:129 39. https://doi.org/ 10.1016/j.energy.2017.07.006.

[23] Braam F, Groß A, Mierau M, Kohrs R, Wittwer C. Coordinated charge management for battery electric vehicles. Comput Sci Res Dev 2016. https:// doi.org/10.1007/s00450-016-0307-6.

[24] Heydarian-Forushani E, Golshan MEH, Shafie-khah M. Flexible interaction of plug-in electric vehicle parking lots for efficient wind integration. Appl Energy 2016;179:338 49. https://doi.org/10.1016/j.apenergy.2016.06.145.

[25] Tulpule PJ, Marano V, Yurkovich S, Rizzoni G. Economic and environmental impacts of a PV powered workplace parking garage charging station. Appl Energy 2013;108:323 32. https://doi.org/10.1016/j.apenergy.2013.02.068.

[26] EEX. Energy_Spot_History_2013. 2015. https://www.eex.com/de/marktdaten/ marktdaten-download. [Accessed 12 January 2015].

[27] Jochem P, Babrowski S, Fichtner W. Assessing CO2 emissions of electric vehicles in Germany in 2030. Transp Res Part A 2015;78:68 83. https://doi.org/ 10.1016/j.tra.2015.05.007.

[28] BMVBS. Mobilitatsstudie. Kraftfahrzeugverkehr in Deutschland 2010, vol. 2010; 2010. Braunschweig.

[29] Schierenbeck S, Graeber D. Ein distanzbasiertes Hochrechnungsverfahren für die Einspeisung aus Photovoltaik. Energiewirtschaftliche Tagesfr 2010;60: 604.

[30] Paraschiv F, Erni D, Pietsch R. The impact of renewable energies on EEX dayahead electricity prices. Energy Policy 2014;73:196 210. https://doi.org/ 10.1016/j.enpol.2014.05.004

[31] Ahmed S, Shapiro A. The sample average approximation method for stochastic programs with integer recourse. Science 2002;12(80):1 24 . doi: 10.1.1.5.3721.

[32] Verweij B, Ahmed S, Kleywegt AJ, Nemhauser G, Shapiro A. The sample average approximation method applied to stochastic routing problems: a computational study. Comput Optim Appl 2003;24:289 333. https://doi.org/ 10.1023/A:1021814225969.

[33] ADACautotest. Nissan Leaf. 2012. https://www.adac.de/_ext/itr/tests/Autotest/ AT4719_Nissan_Leaf/Nissan_Leaf.pdf. [Accessed 24 January 2014].

[34] Meteotest. Meteotest. 2014. http://www.meteotest.ch/. [Accessed 1 March 2014]. 


\section{Repository KITopen}

Dies ist ein Postprint/begutachtetes Manuskript.

Empfohlene Zitierung:

Seddig, K.; Jochem, P.; Fichtner, W.

Integrating renewable energy sources by electric vehicle fleets under uncertainty. 2017. Energy, 141.

doi:10.554/IR/1000077130

Zitierung der Originalveröffentlichung:

Seddig, K.; Jochem, P.; Fichtner, W.

Integrating renewable energy sources by electric vehicle fleets under uncertainty. 2017. Energy, 141, 2145-2153.

doi:10.1016/j.energy.2017.11.140 